\title{
Ideal Cardiovascular Health and Cognitive Test Performance: Testing a Modified Index of Life's Simple 7 Among Older Chinese Adults
}

\author{
Theresa E. Gildner ${ }^{1}$, Nawi $\mathrm{Ng}^{2,3}$, Fan $\mathrm{Wu}^{4}$, Yanfei Guo ${ }^{4}$, J. Josh Snodgrass ${ }^{1}$ and \\ Paul Kowal ${ }^{1,5,6,7 *}$
}

${ }^{1}$ Department of Anthropology, Dartmouth College, Hanover, NH, United States, ${ }^{2}$ Unit of Epidemiology and Global Health, Department of Public Health and Clinical Medicine, Umeå University, Umeå, Sweden, ${ }^{3}$ Centre for Demographic and Ageing Research, Faculty of Social Sciences, Umeå University, Umeå, Sweden, ${ }^{4}$ Shanghai Municipal Center for Disease Control and Prevention, Shanghai, China, ${ }^{5}$ World Health Organization SAGE, Geneva, Switzerland, ${ }^{6}$ Priority Research Centre for Generational Health and Ageing, University of Newcastle, Newcastle, NSW, Australia, ${ }^{7}$ Research Institute for Health Sciences, Chiang Mai University, Chiang Mai, Thailand

\section{OPEN ACCESS}

Edited by:

Colette Joy Browning,

Australian National University, Australia

Reviewed by:

Pradeep Nair,

Central University of

Himachal Pradesh, India

Julie Byles,

University of Newcastle, Australia

*Correspondence:

Paul Kowal

paul.r.kowal@rihes.org

Specialty section:

This article was submitted to

Public Health Education and

Promotion,

a section of the journal

Frontiers in Public Health

Received: 27 July 2018 Accepted: 14 November 2018 Published: 28 November 2018

Citation:

Gildner TE, Ng N, Wu F, Guo Y, Snodgrass JJ and Kowal P (2018) Ideal Cardiovascular Health and Cognitive Test Performance: Testing a

Modified Index of Life's Simple 7 Among Older Chinese Adults.

Front. Public Health 6:352. doi: 10.3389/fpubh.2018.00352
Evidence suggests that cognitive decline in older adults is influenced by cardiovascular health $(\mathrm{CVH})$, with metabolic and vascular mechanisms hypothesized to underlie the etiology of cognitive impairment. Research in high-income nations suggests that improved CVH is linked with decreased cognitive impairment risk, but it is unclear if this pattern is evident in low-income countries. Nationally-representative data collected in China were drawn from the World Health Organization's Study on global AGing and adult health Wave 1 (2007-2010; $n=11,295)$. Seven CVH factors were classified as "ideal" or "not ideal": smoking and drinking frequency, body mass index, physical activity level, blood pressure, diet, and self-reported anxiety. Additionally, scores from five cognitive performance tests (immediate and delayed verbal recall, forward and backward digit span, verbal fluency) were used to create a composite cognitive function variable. Linear regression analyses tested whether ideal $\mathrm{CVH}$ measures were associated with higher composite cognitive performance, controlling for sociodemographic factors. As hypothesized, ideal $\mathrm{CVH}$ was generally associated with higher cognitive performance. Low anxiety levels and reliable access to sufficient food (including produce) were particularly associated with higher cognitive function. These results suggest early detection and controlling modifiable $\mathrm{CVH}$ risks may protect aging individuals in China from cognitive decline.

Keywords: cardiovascular disease risk factors, dementia prevention, global aging, lifestyle, heart disease

\section{INTRODUCTION}

The global population is currently experiencing a rapid aging transition, largely due to increased life expectancies and decreased fertility in many countries; however, global aging and health patterns are not uniform. At the start of the Twenty-first century, the number of Chinese adults aged 60 years and older reached an estimated 130 million, roughly $10 \%$ of the total Chinese population and $21 \%$ of the world's older population $(1,2)$. This trend is expected to continue such that the population of older adults in China will nearly triple and comprise $25 \%$ of the national population by 
2030 (2), presenting considerable opportunities and challenges for China in coming decades. To put this into context, China had more cases of Alzheimer's disease in 2010 than any other country in the world (3). Over the last three decades, the prevalence of both Alzheimer's disease and vascular dementia has significantly increased, and it appears previous work has underestimated the burden and growth of dementia in China (4).

This increased disease burden will challenge healthcare systems to reform as they seek to meet the demands of patients and their caregivers in the coming years. It is therefore critical to identify potential interventions to promote healthy aging and reduce both the economic and social costs of dementia. Evidence suggests that improving cardiovascular health $(\mathrm{CVH})$ among older adults represents one such prevention strategy. Factors associated with poor vascular health (such as smoking, obesity, low physical activity levels) are associated with cognitive aging $(5,6)$. Specifically, vascular and metabolic mechanisms may underlie the etiology of cognitive impairment, and poor vascular and metabolic health likely contribute to cognitive deficit at older ages (7). Models linking poor vascular/metabolic health to cognitive performance indicate that potential pathways between poor $\mathrm{CVH}$ and cognitive deficit include metabolic imbalance, altered distribution of cerebral blood flow, nerve demyelination, and microinfarction (8). Several factors that impair vascular and metabolic health have also been linked with increased dementia risk in older adults: smokers experience a significantly more pronounced decline in cognitive function, flexibility, and speed (9); high alcohol consumption has been associated with poorer neurological function (10); and, overweight and obese adults display significantly lower cognitive function compared to healthy weight individuals $(8,11)$.

Conversely, physical activity level (PAL) appears to be related to improved neuronal plasticity and the release of hormones linked with neuronal creation and function; physical inactivity may therefore exacerbate cognitive decline (12). High blood pressure also appears to be associated with an increased risk of cognitive decline, including neural atrophy and lesions (13). Thus, hypertension may contribute to dementia risk (13). Further, poor diet (including low fruit and vegetable intake and the inability to acquire sufficient food) is linked with diminished cognitive function via impaired metabolic and vascular health, increasing subsequent risk of diabetes and coronary heart disease (14). Finally, chronic psychological stress is associated with poor cardiovascular health, potentially leading to cognitive decline (15).

Prior studies have combined several of these $\mathrm{CVH}$ risk factors into a panel that represents overall CVH: Life's Simple 7, a proxy measure used to test the cumulative influence of $\mathrm{CVH}$ on cognitive performance in older persons (6). Previous findings support the hypothesis that individuals with healthier $\mathrm{CVH}$ measures are more resistant to impaired cognitive processing speed, executive function, and episodic memory (6). However, this work has focused primarily on populations from high-income nations. It is unclear whether these patterns are also evident in lower income nations.
This research is especially important given the substantial increases in older adults residing in LMICs, such as China, expected to occur in coming years (2). It is therefore necessary to determine whether interventions designed to improve cognitive performance during aging through targeting $\mathrm{CVH}$ factors can be expected to have the same effects in all populations.

The present study addresses this need by examining the links between $\mathrm{CVH}$ factors and cognitive performance in China using data from the World Health Organization Study on global AGing and adult health (SAGE) Wave 1 (16). This research clarifies how a modified panel of seven factors known to influence $\mathrm{CVH}$ (smoking, alcohol consumption, body mass index [BMI; calculated from individual height and weight values], PAL, blood pressure, diet, and self-reported anxiety) is linked with specific measures of cognitive performance among older Chinese individuals, while controlling for sex, age, wealth, and education level. These results will help determine whether $\mathrm{CVH}$ is linked with poor cognitive function in China. These findings also have potentially important clinical applications, including the identification of $\mathrm{CVH}$ factors most strongly linked with cognitive deficits in this population. This knowledge is required for the development of interventions designed to successfully improve $\mathrm{CVH}$ and subsequently reduce dementia risk. We hypothesize that the combined ideal measure score of the seven CVH factors will be positively associated with performance on a battery of cognitive function tests.

\section{MATERIALS AND METHODS \\ Study Design and Participants}

A nationally-representative sample of adults $\geq 50$ years old ( $n=13,367)$ were collected using a multistage stratified cluster sample design $(16,17)$. In-person interviews were used to collect household and individual level data between 2007 and 2010. Specifically, eight of China's 22 provinces were randomly selected. One county in the rural regions and one district/city in the urban regions was then selected at random from each province. Next, four townships in each selected county and four community blocks in each selected city were selected using probability proportional to size (PPS) sampling, for a total of 64 primary sampling units. Two villages/enumeration areas per township/community were then selected using PPS sampling, for a total of 128 secondary sampling units. Two residential blocks were then selected from each village/neighborhood community using random cluster sampling, for a total of 256 tertiary sampling units. Finally, 84 households were randomly selected (with a 95\% response rate) from each sampled residential block using simple random sampling. Post-stratification corrections were applied to these weights to compensate for under-coverage. All analyses are carried out using these weights. At the time of data collection, China was classified as a lower middle-income nation (18).

\section{Ethical Approval}

SAGE China was approved by the Chinese Center for Disease Control and Prevention Ethical Review Committee, 
and World Health Organization's Ethical Review Committee. Written informed consent was obtained from all study participants.

\section{Measures of Cardiovascular Health}

To test associations between $\mathrm{CVH}$ and cognitive function, seven measures associated with $\mathrm{CVH}$ were included in the analyses: smoking, alcohol consumption, BMI, PAL, blood pressure, diet, and self-reported anxiety. Each of these factors was classified as either "ideal" or "not ideal." This approach was largely based on criteria defined by the American Heart Association (6). First, ideal smoking was defined as never smoked (6). Second, ideal alcohol consumption was classified as do not drink daily (10). Third, ideal BMI was calculated from measured height and weight and was defined as $18.5-22.9 \mathrm{~kg} / \mathrm{m}^{2}$, based on the modified WHO definition of normal, healthy BMI in Asian populations (19).

Fourth, ideal PAL was defined as $\geq 150 \mathrm{~min} /$ week (6). Total PAL was calculated from interview data using questions from the Global Physical Activity Questionnaire (GPAQ) to determine self-report physical activity patterns (20). This questionnaire collects information about physical activity patterns across a range of daily activities. Participants reported the amount of time during a typical day spent in vigorous-intensity activities (those that caused large increases in breathing or heart rate) as part of their work, in moderate-intensity activities (those that caused small increases in breathing or heart rate) as part of their work, in vigorous-intensity activities during leisure time, and in moderate-intensity activities during leisure time. Selfreported time spent in vigorous or moderate exercise for both work and leisure were combined to create a composite PAL measure ( $\mathrm{min} /$ week).

Fifth, ideal overall blood pressure was defined as exhibiting both ideal SBP $(<120 \mathrm{~mm} \mathrm{Hg})$ and ideal DBP $(<80 \mathrm{~mm}$ $\mathrm{Hg}$ ) (6). Participant systolic (SBP) and diastolic blood pressure (DBP) were individually measured three times using a Boso Medistar Wrist Blood Pressure Monitor Model S. The three SBP values were averaged together to create a composite SBP measure; likewise, the three DBP values were combined to create an average DBP measure. Sixth, ideal diet was defined as typically consuming $\geq 5$ servings of fruit or vegetables daily combined with reporting access to an adequate amount of food (6). Finally, given the negative effects of chronic anxiety on $\mathrm{CVH}$ (15), ideal anxiety levels were defined as reporting either no or mild anxiety, conversely not ideal anxiety was defined as reporting moderate, severe, or extreme levels of anxiety. Specifically, respondents were asked: "Overall in the last 30 days, how much of a problem did you have with worry or anxiety?" The number of ideal $\mathrm{CVH}$ factors was summed for each participant (range of $0-7$ ideal characteristics) and this continuous variable was used as the primary predictor of interest during analysis.

\section{Measures of Cognitive Function}

Five cognitive function assessments were used to create a summary variable of cognitive performance for each individual, with higher values indicating better cognitive function. These tests included immediate and delayed verbal recall, forward and backward digit span, and verbal fluency. During the immediate verbal recall test, interviewers read a list of 10 words aloud and asked the participants to immediately recall as many words as they could in $1 \mathrm{~min}$. Three trials of this assessment were performed and the average test score was calculated. The interviewer then administered other cognitive tests, after which delayed recall ability was determined by asking subjects to remember the list of words without the interviewer reading the list again. The digit span test required participants to repeat back progressively longer series of numbers; the total score was recorded as the longest digit span repeated without error. This process was then repeated, but with the respondent repeating new sets of increasingly longer digit spans in reverse. The verbal fluency test consisted of naming as many animals as possible in $1 \mathrm{~min}$; the final verbal fluency score was correct responses minus errors.

Preliminary analysis indicated that these tests were moderately correlated (Pearson correlation scores ranging from 0.327 to 0.706 ). Thus, principal component analysis was used to develop a composite cognitive performance from the battery of tests. This analysis computed component scores and weighted the contribution of each individual test to overall cognitive performance. The composite factor score resulting from this analysis (for each participant) was used as a measure of overall cognitive function during hypothesis testing.

\section{Participant Characteristics}

Individual characteristics known to influence cognitive performance were controlled for in all analyses. Evidence suggests that sex and age influence the extent of cognitive decline in older adults (21). Socio-economic factors appear to affect cognition, such that individuals with lower education and household income levels experience an increased risk of cognitive decline during aging (21). In addition, individuals living in rural settings have been shown to exhibit a higher dementia prevalence compared to urban areas (22). Reported annual household income was combined with an index of durable goods ownership, dwelling characteristics, and access to services; this wealth variable was then classified into household income quintiles for the analyses. Reported highest attained education level was standardized using the International Standard Classification of Education (23). Individual education level was then categorized as: (1) no formal schooling; (2) less than a high school degree; or, (3) high school degree or beyond.

\section{Statistical Analyses}

All analyses were conducted using Stata version 14, results were regarded as significant at $p<0.05$. Household and individual weights were post-stratified according to countryspecific population data (17). Linear regressions were conducted to test the hypothesis and evaluate the relative contribution of the total $\mathrm{CVH}$ score to composite cognitive performance score, while controlling for sociodemographic factors. Additional linear regressions were run to determine the associations between individual $\mathrm{CVH}$ components (categorized as ideal vs. not 
ideal) and composite cognitive performance. Individuals missing one or more variables were excluded from regression analysis $(n=2,071)$. Preliminary analysis indicated individuals missing data tended to be slightly older (mean of 62.1 years vs. 60.3 years), but otherwise there were no marked participant characteristic differences between individuals missing data and those included in the analysis. In addition, a single individual had zero $\mathrm{CVH}$ ideal traits, every other participant had at least one trait. This outlier disrupted the general linearity of the data and was there removed from analysis, resulting in a final sample of 11,295 participants.

\section{RESULTS}

\section{Descriptive Statistics}

Table 1 shows the characteristics of the study population (Table 1). The study population contained slightly more females (53.6\%) than males (46.4\%), but was roughly equally split between urban (50.6\%) and rural (49.4\%) households. Most participants had received some formal schooling, but had not earned a high school degree or the equivalent (59.0\%). Over half the study participants reported ideal smoking (66.6\%), drinking (92.6\%), physical activity (60.5\%), diet (87.1\%), and anxiety levels (95.9\%). Conversely, less than half of the subjects exhibited ideal BMI (38.9\%) or BP (12.3\%). Mean age was 63 years old and average number of combined ideal $\mathrm{CVH}$ measures was 4.5 $(S D=1.0)$. Cognitive test scores varied based on test type, from the wide range of scores evident on the verbal fluency test (mean of 12.74, range of $0-68$ ) to the lower scores recorded on the backward digit span test (mean of 3.40, range of $0-8$ ).

\section{Combined CVH Measures and Composite Cognitive Function Score}

Total number of ideal CVH factors significantly contributed to variation in cognitive test results, although the association between total $\mathrm{CVH}$ traits and the composite cognitive score appears to be modest (Table 2). Still, a positive relationship was observed between number of $\mathrm{CVH}$ ideals and cognitive performance $(\mathrm{B}=0.03, P<0.05)$, indicating that a higher number of individual $\mathrm{CVH}$ traits corresponded to higher overall cognitive performance.

\section{Individual CVH Measures and Composite Cognitive Function Score}

Interestingly, regressions examining the individual contributions of ideal smoking, drinking, BMI, PAL, and BP to composite cognitive performance variation were not significantly related to the composite cognitive test scores (Table 3 ). Only ideal $\operatorname{diet}(\mathrm{B}=0.180, P<0.001)$ and ideal anxiety $(\mathrm{B}=0.308$, $P<0.001)$ classifications were significantly associated with cognitive performance. As expected, ideal diet and ideal anxiety levels were related to higher overall cognitive performance.

\section{DISCUSSION}

The results of this study generally support the hypothesis that ideal measures of the seven $\mathrm{CVH}$ factors are positively
TABLE 1 | Description of the Chinese study population (unweighted data), SAGE Wave 1 (2007-2010), $n=11,295$ individuals. ${ }^{a, b}$.

\begin{tabular}{|c|c|}
\hline Variables & $n(\%)$ \\
\hline Male sex & $5,242(46.4)$ \\
\hline Urban dwelling & $5,711(50.6)$ \\
\hline Income quintile 1 (low) & 2,196 (19.4) \\
\hline Income quintile 2 & 2,254 (20.0) \\
\hline Income quintile 3 & 2,283 (20.2) \\
\hline Income quintile 4 & 2,365 (20.9) \\
\hline Income quintile 5 (high) & 2,197 (19.5) \\
\hline No formal education & 2,558 (23.6) \\
\hline Less than high school & $6,660(59.0)$ \\
\hline High school or beyond & $1,967(17.4)$ \\
\hline Ideal smoking & 7,519 (66.6) \\
\hline Ideal drinking & $10,457(92.6)$ \\
\hline Ideal BMI & 4,397 (38.9) \\
\hline Ideal PAL & $6,828(60.5)$ \\
\hline Ideal BP & 1,384 (12.3) \\
\hline Ideal diet & $9,835(87.1)$ \\
\hline Ideal stress & 10,835 (95.9) \\
\hline \multicolumn{2}{|l|}{ MEAN (RANGE) } \\
\hline Age & $62.9(50-95)$ \\
\hline Combined ideals score & $4.5(-3.62-3.56)$ \\
\hline Immediate verbal recall & $5.62(0-10)$ \\
\hline Delayed verbal recall & $4.97(0-10)$ \\
\hline Forward digit span & $7.03(0-9)$ \\
\hline Backward digit span & $3.40(0-8)$ \\
\hline Verbal fluency & $12.74(0-68)$ \\
\hline
\end{tabular}

${ }^{a}$ Body Mass Index (BMI), Blood Pressure (BP), Physical Activity Level (PAL)

${ }^{b}$ Ideal cardiovascular health measures:

Ideal smoking $=$ never smoked

Ideal drinking $=$ do not drink daily

Ideal $B M I=18.5-22.9 \mathrm{~kg} / \mathrm{m}^{2}$

Ideal $P A L \geq 150 \mathrm{~min} /$ week

Ideal $\mathrm{BP}=$ ideal SBP $(<120 \mathrm{~mm} \mathrm{Hg})$ and ideal $\mathrm{DBP}(<80 \mathrm{~mm} \mathrm{Hg})$

Ideal diet $=$ consuming $\geq 5$ servings of fruit and/or vegetables daily combined with reporting access to an adequate amount of food

Ideal stress = reporting either no or mild anxiety.

associated with cognitive performance on a battery of tests. Furthermore, our findings are consistent with the positive linear associations documented between ideal $\mathrm{CVH}$ metrics and mortality (24) and other non-cardiovascular outcomes (25) in meta-analyses.

\section{Overall CVH and Cognitive Performance}

The total number of $\mathrm{CVH}$ ideal characteristics was positively related to composite cognitive performance score (Table 2). As expected, a higher number of ideal $\mathrm{CVH}$ traits corresponded with higher composite cognitive function scores, supporting previous findings in high-income nations $(5,6,26)$, in addition to a meta-study of both US and non-US populations (27). Therefore, regardless of where implemented, a consistent pattern evident between a higher number of ideal $\mathrm{CVH}$ traits and lower prevalence of cognitive impairment-similar to what was found 
in our study. There are several potential explanations for the observed relationship between $\mathrm{CVH}$ and composite cognitive performance.

TABLE 2 | Linear regression modeling the association between composite cognitive score and total number of $\mathrm{CVH}$ factors (ranging from 1 to 7 ideal traits) in the Chinese study population (weighted data), SAGE Wave 1 (2007-2010).

\begin{tabular}{lc}
\hline Variable & $\boldsymbol{\beta}$ (SE) \\
\hline Sex & $-0.106(0.034)^{\star \star}$ \\
Age: 60-69 years old & $-0.219(0.026)^{\star \star \star}$ \\
70-79 years old & $-0.498(0.032)^{\star \star \star}$ \\
80+ years old & $-0.931(0.056)^{\star \star \star}$ \\
Income quintile: 1 & $-0.476(0.066)^{\star \star \star}$ \\
2 & $-0.384(0.060)^{\star \star \star}$ \\
3 & $-0.294(0.062)^{\star \star \star}$ \\
4 & $-0.107(0.050)^{\star}$ \\
Household setting & $-0.215(0.042)^{\star \star \star}$ \\
Education: $<$ high school & $0.484(0.020)^{\star \star \star}$ \\
High school or beyond & $0.872(0.052)^{\star \star \star}$ \\
Total number of ideal CVH factors & $0.031(0.015)^{\star}$ \\
\hline
\end{tabular}

Parameter estimates ( $\beta$ ) with standard error (SE). ${ }^{a-c}$

${ }^{a}$ Cardiovascular Health $(\mathrm{CVH})$

${ }^{b}$ Comparisons are statistically significant at: ${ }^{\star} P<0.05,{ }^{* \star} P<0.01,{ }^{* \star *} P<0.001$

${ }^{c}$ Reference groups used in the creation of pacifier codes for each categorical variable:

Sex $=0$ (male)

Age $=50-59$ years old

Income quintile $=5$ (high income)

Household setting $=0$ (urban)

Education level = no formal schooling.
First, previous research indicates that improved cardiovascular health enhances vascular health and brain tissue perfusion, resulting in cognitive gains (28). High levels of general $\mathrm{CVH}$ therefore likely support learning and cognitive function later in life. Moreover, better vascular function also results from the avoidance of risky behaviors (like smoking and heavy drinking). These risky behaviors introduce toxins into the bloodstream, resulting in the development of atherosclerosis (a main contributor to cardiovascular disease) and causing systematic inflammation that impairs cognitive function (5). Thus, improved levels of cumulative CVH likely offer some protection from cognitive impairment during senescence.

\section{Individual CVH Measures and Cognitive Performance}

Unexpectedly, when the CVH measures were considered separately only ideal diet and anxiety were significantly associated with composite cognitive performance. These findings are likely due to the importance of proper nutrition to mental acuity and the detrimental effects of chronic anxiety. While fruit and vegetable intake is not a comprehensive measure of overall diet, it provides a macro-level indication of diet quality and key components of the diet in relation to disease burden. The association between produce consumption and cognitive function documented here is consistent with results from analyses of SAGE data conducted by other analysts. Specifically, previous work indicates that the consumption of both fruit and vegetables is related to higher cognitive health among SAGE participants (29). It should also be noted that a preliminary

TABLE 3 | Linear regressions modeling associations between composite cognitive score (the dependent variable) and each individual CVH factor (the final independent variable entered in each model) in the Chinese study population (weighted data), SAGE Wave 1 (2007-2010).

\begin{tabular}{|c|c|c|c|c|c|c|c|c|c|c|}
\hline & Sex & Age & $\begin{array}{c}\text { Income } \\
\text { quintile: } 1\end{array}$ & $\begin{array}{c}\text { Income } \\
\text { quintile: } 2\end{array}$ & $\begin{array}{c}\text { Income } \\
\text { quintile: } 3\end{array}$ & $\begin{array}{c}\text { Income } \\
\text { quintile: } 4\end{array}$ & $\begin{array}{l}\text { Household } \\
\text { setting }\end{array}$ & $\begin{array}{c}\text { Education: } \\
\text { < high } \\
\text { school }\end{array}$ & $\begin{array}{c}\text { Education: high } \\
\text { school or } \\
\text { beyond }\end{array}$ & $\begin{array}{c}\text { Ideal CVH } \\
\text { trait }\end{array}$ \\
\hline Ideal Smoking & $\begin{array}{c}-0.092 \\
(0.034)^{\star \star}\end{array}$ & $\begin{array}{c}-0.029 \\
(0.002)^{\star \star \star}\end{array}$ & $\begin{array}{c}-0.460 \\
(0.068)^{\star \star \star \star}\end{array}$ & $\begin{array}{c}-0.369 \\
(0.061)^{\star \star \star}\end{array}$ & $\begin{array}{c}-0.280 \\
(0.063)^{\star \star \star}\end{array}$ & $\begin{array}{c}-0.098 \\
(0.049)\end{array}$ & $\begin{array}{c}-0.225 \\
(0.043)^{\star \star \star}\end{array}$ & $\begin{array}{c}0.472 \\
(0.021)^{\star \star \star}\end{array}$ & $\begin{array}{c}0.848 \\
(0.052)^{\star * \star}\end{array}$ & $\begin{array}{c}0.006 \\
(0.331)\end{array}$ \\
\hline Ideal Drinking & $\begin{array}{c}-0.095 \\
(0.030)^{\star \star}\end{array}$ & $\begin{array}{c}-0.029 \\
(0.002)^{\star \star \star}\end{array}$ & $\begin{array}{c}-0.462 \\
(0.068)^{\star \star * \star}\end{array}$ & $\begin{array}{c}-0.371 \\
(0.062)^{\star \star \star}\end{array}$ & $\begin{array}{c}-0.278 \\
(0.063)^{\star \star \star}\end{array}$ & $\begin{array}{c}-0.098 \\
(0.049)\end{array}$ & $\begin{array}{c}-0.222 \\
(0.043)^{\star \star \star}\end{array}$ & $\begin{array}{c}0.472 \\
(0.021)^{\star \star \star}\end{array}$ & $\begin{array}{c}0.848 \\
(0.052)^{\star \star \star}\end{array}$ & $\begin{array}{c}0.038 \\
(0.038)\end{array}$ \\
\hline Ideal BMI & $\begin{array}{c}-0.090 \\
(0.028)^{\star \star}\end{array}$ & $\begin{array}{c}-0.029 \\
(0.002)^{\star \star \star}\end{array}$ & $\begin{array}{c}-0.458 \\
(0.067)^{\star \star \star}\end{array}$ & $\begin{array}{c}-0.368 \\
(0.061)^{\star \star \star}\end{array}$ & $\begin{array}{c}-0.279 \\
(0.063)^{\star \star \star}\end{array}$ & $\begin{array}{c}-0.098 \\
(0.049)\end{array}$ & $\begin{array}{c}-0.224 \\
(0.042)^{\star \star \star}\end{array}$ & $\begin{array}{c}0.471 \\
(0.021)^{\star \star \star}\end{array}$ & $\begin{array}{c}0.849 \\
(0.052)^{\star \star \star}\end{array}$ & $\begin{array}{c}-0.018 \\
(0.019)\end{array}$ \\
\hline Ideal PAL & $\begin{array}{c}-0.089 \\
(0.028)^{\star \star}\end{array}$ & $\begin{array}{c}-0.029 \\
(0.002)^{\star \star \star}\end{array}$ & $\begin{array}{c}-0.462 \\
(0.065)^{\star \star \star}\end{array}$ & $\begin{array}{c}-0.371 \\
(0.058)^{\star \star \star}\end{array}$ & $\begin{array}{c}-0.281 \\
(0.060)^{\star \star \star}\end{array}$ & $\begin{array}{l}-0.099 \\
(0.047)^{*}\end{array}$ & $\begin{array}{c}-0.227 \\
(0.044)^{\star \star \star}\end{array}$ & $\begin{array}{c}0.472 \\
(0.021)^{\star \star \star}\end{array}$ & $\begin{array}{c}0.850 \\
(0.052)^{\star \star \star}\end{array}$ & $\begin{array}{c}0.012 \\
(0.046)\end{array}$ \\
\hline $\begin{array}{l}\text { Ideal } \\
\mathrm{BP}\end{array}$ & $\begin{array}{c}-0.089 \\
(0.028)^{\star \star}\end{array}$ & $\begin{array}{c}-0.029 \\
(0.002)^{\star \star \star}\end{array}$ & $\begin{array}{c}-0.461 \\
(0.068)^{\star \star \star}\end{array}$ & $\begin{array}{c}-0.370 \\
(0.062)^{\star \star \star}\end{array}$ & $\begin{array}{c}-0.280 \\
(0.063)^{\star \star \star}\end{array}$ & $\begin{array}{c}-0.098 \\
(0.049)\end{array}$ & $\begin{array}{c}-0.224 \\
(0.043)^{\star \star \star}\end{array}$ & $\begin{array}{c}0.472 \\
(0.021)^{\star \star \star}\end{array}$ & $\begin{array}{c}0.849 \\
(0.052)^{\star \star \star}\end{array}$ & $\begin{array}{c}0.021 \\
(0.025)\end{array}$ \\
\hline Ideal Diet & $\begin{array}{c}-0.090 \\
(0.028)^{\star \star}\end{array}$ & $\begin{array}{c}-0.028 \\
(0.002)^{\star \star \star *}\end{array}$ & $\begin{array}{c}-0.451 \\
(0.068)^{\star \star \star \star}\end{array}$ & $\begin{array}{c}-0.366 \\
(0.062)^{\star \star \star}\end{array}$ & $\begin{array}{c}-0.279 \\
(0.063)^{\star \star \star}\end{array}$ & $\begin{array}{l}-0.100 \\
(0.049)^{*}\end{array}$ & $\begin{array}{c}-0.225 \\
(0.043)^{\star * \star}\end{array}$ & $\begin{array}{c}0.467 \\
(0.021)^{\star \star \star}\end{array}$ & $\begin{array}{c}0.841 \\
(0.053)^{\star \star \star}\end{array}$ & $\begin{array}{c}0.130 \\
(0.049)^{\star}\end{array}$ \\
\hline Ideal Anxiety & $\begin{array}{c}-0.087 \\
(0.029)^{\star \star}\end{array}$ & $\begin{array}{c}-0.028 \\
(0.002)^{\star \star \star}\end{array}$ & $\begin{array}{c}-0.451 \\
(0.067)^{\star \star \star}\end{array}$ & $\begin{array}{c}-0.362 \\
(0.061)^{\star \star \star}\end{array}$ & $\begin{array}{c}-0.277 \\
(0.063)^{\star \star \star}\end{array}$ & $\begin{array}{c}-0.096 \\
(0.049)\end{array}$ & $\begin{array}{c}-0.226 \\
(0.042)^{\star \star \star}\end{array}$ & $\begin{array}{c}0.469 \\
(0.020)^{\star \star \star}\end{array}$ & $\begin{array}{c}0.846 \\
(0.052)^{\star \star \star *}\end{array}$ & $\begin{array}{c}0.242 \\
(0.077)^{\star \star}\end{array}$ \\
\hline
\end{tabular}

Full models including all covariates are presented; parameter estimates ( $\beta$ ) with standard error (SE). ${ }^{a-c}$

${ }^{a}$ Body Mass Index (BMI), Blood Pressure (BP), Physical Activity Level (PAL)

${ }^{b}$ Comparisons are statistically significant at: ${ }^{*} P<0.05,{ }^{* *} P<0.01,{ }^{* \star *} P<0.001$

${ }^{c}$ Reference groups used in the creation of pacifier codes for each categorical variable:

Sex $=0$ (male)

Income quintile $=5$ (high income)

Household setting $=0$ (urban)

Education level = no formal schooling. 
analysis testing for an interaction between BMI and diet in relation to cognitive function was not significant $(p=0.711)$, indicating that diet influences cognition independent of any relationship with BMI.

There are several possible mechanisms accounting for this association. For instance, it is possible that antioxidants in fruit and vegetables play an important role in preventing oxidative stress (e.g., caused by free radicals), thereby protecting neural cells from damage (30-32). Similarly, key nutrients found in produce (i.e., zinc) appear to directly protect neurological functions (33). Fruits and vegetables are also high in fiber, which may support a healthy gut microbiota linked with higher cognitive health (34). It should also be noted that a preliminary analysis testing for an interaction between BMI and diet in relation to cognitive function was not significant $(p=0.711$ ), indicating that diet influences cognition independent of any relationship with BMI.

Likewise, the association between cognitive function and anxiety documented here may be explained by multiple factors. First, the energetic costs of chronic anxiety may contribute to this relationship. Chronic anxiety has long been known to affect the proper processing, storage, and mobilization of energetic reserves (i.e., glucose availability), which may have implications for energetically-expensive cognitive functions (35). Chronically elevated stress hormones have also been shown to alter brain cell structure and lead to a loss of neurons, impairing various aspects of cognition, such as memory (35). Moreover, personality traits (e.g., neuroticism) have been linked with self-reported anxiety and have also been connected to poor cognitive performance in older adults $(36,37)$. Aspects of participant personality may therefore also contribute to anxiety risk and subsequent cognitive decline.

The promotion of increased produce consumption and techniques to reduce anxiety levels may therefore represent promising strategies to support healthy cognitive function among older Chinese adults. This would also support findings in China which suggest that improvements in diet and physical activity are needed to improve $\mathrm{CVH}$ and prevent strokes (38). It is unknown why other $\mathrm{CVH}$ factors-identified in studies of other populations-did not significantly influence cognitive performance in this sample. We speculate that this may due to a combination of population characteristics and measurement techniques. For example, a relatively low percentage of participants in the study population were obese (14.3\%); it is therefore possible that BMI does not have the same effect on cognitive performance as has been observed in wealthier nations with higher prevalence of obesity over the lifespan. Likewise, a large proportion of participants reported never having smoked $(66.6 \%)$ or having consumed alcohol $(69.1 \%)$ in their lifetimes. Again, this may decrease our ability to detect the influence of these behaviors on cognitive function.

The high rate of ideal $\mathrm{CVH}$ traits documented among the study population is consistent with recent work indicating that, compared to other populations outside of the United States, a larger proportion of Chinese adults exhibit 6-7 ideal $\mathrm{CVH}$ traits (15\% of the study population; as defined using American Heart Association CVH measures) (27). Older Chinese adults may therefore generally exhibit higher levels of $\mathrm{CVH}$, relative to older adults in other groups. Still, in concordance with the lack of significant associations between individual $\mathrm{CVH}$ traits and cognitive performance documented here, a review of how $\mathrm{CVH}$ interventions affect overall health in LMICs (including improvements in physical activity and body weight) found inconsistent patterns cross-culturally (39). This inconsistency suggests that the influence of individual $\mathrm{CVH}$ measures on health (including cognitive function) may vary across populations. Furthermore, the seven $\mathrm{CVH}$ factors used in the present study are interrelated; thus, a composite measure of overall $\mathrm{CVH}$ may function as a more reliable predictor for health outcomes.

\section{Limitations and Strengths}

The present study has several limitations. First, because the data are cross-sectional, it is not possible to determine causality between the variables assessed. It is therefore conceivable that cognitive impairment might cause poor $\mathrm{CVH}$ (due to changes in diet and activity patterns resulting from dementia). Second, while the battery of cognitive tests used to determine cognitive performance has been tested and used in numerous countries (6, $11,14)$ and was tested during preliminary SAGE data collection, these cognitive measures were not developed in China. In the future, a more diverse range of cognitive tests may better capture different aspects of cognitive performance.

Furthermore, PALs were determined using self-report questionnaire-based data. Although this is a commonly used measure, self-report data often overestimates physical activity levels. Finally, this study was unable to use the exact 'Life's Simple 7' CVH panel developed by the American Heart Association (6). Two of the variables included in this original panel (total cholesterol and fasting plasma glucose levels) were not collected as part of the SAGE Wave 1 study protocol. Two other factors known to influence CVH (drinking frequency and self-reported anxiety) were included in their place, potentially altering the comparability of results to similar analyses in other countries.

Despite these limitations, this study provides a unique examination of the associations between $\mathrm{CVH}$ and cognitive performance in older Chinese adults. Prior research testing these relationships has typically been limited to high-income countries and reliant on data collected from small and non-representative population samples. Conversely, the SAGE sample is large and captures the range of living conditions across China (16). Further, the use of self-reported anxiety levels in this study reveals the influence of mental health and perceived well-being on health outcomes, indicating this inexpensive measure may be a useful tool in future population risk assessments.

\section{CONCLUSION}

These results support previous findings in high-income populations and suggest that general $\mathrm{CVH}$ is positively associated with cognitive test performance in older Chinese adults. Future research should therefore test whether increasing total number of patient CVH ideal traits is beneficial for cognitive function in an aging cohort. Decreasing the rate of neurological decline and promoting healthy cognitive aging will continue 
to be of utmost importance in coming years as the population of China continues to age and dementia rates increase. An increased focus on these topics is required to determine how targeting chronic disease risk factors (including poor $\mathrm{CVH}$ ) can decrease physical and mental health burdens on older adult populations, thus contributing to improved health during aging.

\section{DATA AVAILABILITY STATEMENT}

The data that support the findings of this study are openly available in WHO Multi-Country Studies Data Archive at http:// apps.who.int/healthinfo/systems/surveydata/index.php/catalog/ 13

\section{AUTHOR CONTRIBUTIONS}

TG carried out background research, performed the statistical analysis, and drafted the manuscript. NN participated in designing the statistical methods used and helped to draft the manuscript. PK and FW conceived of the study and helped to

\section{REFERENCES}

1. He W, Goodkind D, Kowal P. US Census Bureau, International Population Reports. P95/16-1, An Aging World: 2015. [Internet, 2016]. (2015). Available online at: https://www.census.gov/library/publications/2016/demo/P95-16-1. html (Accessed March 23, 2018)

2. United Nations Department of Economic and Social Affairs, UNDESA. World Population Prospects: The 2017 Revision. New York, NY: United Nations [Internet, 2017]. (2017). Available online at: https://www.un.org/ development/desa/publications/world-population-prospects-the-2017revision.html (Accessed March 23, 2018).

3. ADI. World Alzheimer Report. London: Alzheimer's Disease International [Internet, 2009]. (2009). Available online at: https://www.alz.co.uk/research/ files/WorldAlzheimerReport-ExecutiveSummary.pdf (Accessed March 23, 2018)

4. Chan KY, Wang W, Wu JJ, Liu L, Theodoratou E, Car J, et al. Epidemiology of Alzheimer's disease and other forms of dementia in China, 1990-2010: a systematic review and analysis. Lancet (2013) 381:2016-23. doi: 10.1016/s0140-6736(13)60221-4

5. Crichton GE, Elias MF, Davey A, Alkerwi AA. Cardiovascular health and cognitive function: the Maine-Syracuse Longitudinal Study. PLoS ONE (2014) 9:e89317. doi: 10.1371/journal.pone.0089317

6. Gardener H, Clinton BW, Chuanhui D, Ken C, Janet D, Micaela N, et al. Ideal cardiovascular health and cognitive aging in the Northern Manhattan Study. $J$ Am Heart Assoc. (2016) 5:e002731. doi: 10.1161/jaha.115.002731

7. Kling MA, Trojanowski JQ, Wolk DA, Lee VM, Arnold SE. Vascular disease and dementias: paradigm shifts to drive research in new directions. Alzheimers Dement. (2013) 9:76-92. doi: 10.1016/j.jalz.2012.02.007

8. Elias MF, Elias PK, Sullivan LM, Wolf PA, D'agostino RB. Lower cognitive function in the presence of obesity and hypertension: the Framingham heart study. Int J Obes. (2003) 27:260. doi: 10.1038/sj.ijo.802225

9. Anstey KJ, von Sanden C, Salim A, O’Kearney R. Smoking as a risk factor for dementia and cognitive decline: a meta-analysis of prospective studies. Am J Epidemiol. (2007) 166:367-78. doi: 10.1093/aje/kwm116

10. Mukamal KJ, Longstreth WT, Mittleman MA, Crum RM, Siscovick DS. Alcohol consumption and subclinical findings on magnetic resonance imaging of the brain in older adults: the cardiovascular health study. Stroke (2001) 32:1939-46. doi: 10.1161/hs0901.095723

11. Wolf PA, Beiser A, Elias MF, Au R, Vasan RS, Seshadri S. Relation of obesity to cognitive function: importance of central obesity and synergistic influence draft the manuscript. YG and JS participated in the study design and helped draft the manuscript. All authors read and approved the final manuscript.

\section{FUNDING}

This work was funded by the Science and Technology Commission of Shanghai Municipality under Grant No. 10XD1403600; Shanghai Municipal Organization Department and the Shanghai Bureau of Human Resource and Social Security; the World Health Organization; and the US National Institute on Aging through Interagency Agreements (OGHA 04034785; YA1323-08-CN-0020; Y1-AG-1005-01) and through a research grant (R01-AG034479).

\section{ACKNOWLEDGMENTS}

We thank Nirmala Naidoo for help with data management, all the study respondents, and the study PIs and teams. WHO's Study on global AGEing and adult health is supported by the respective governments in collaborating countries and WHO. of concomitant hypertension. Framingham Heart Study. Curr Alzheimer Res. (2007) 4:111-6. doi: 10.2174/156720507780362263

12. Laurin D, Verreault R, Lindsay J, MacPherson K, Rockwood K. Physical activity and risk of cognitive impairment and dementia in elderly persons. Arch Neurol. (2001) 58:498-504. doi: 10.1001/archneur.58.3.498

13. Launer LJ, Hughes T, Yu B, Masaki K, Petrovitch H, Ross GW, et al. Lowering midlife levels of systolic blood pressure as a public health strategy to reduce late-life dementia: perspective from the honolulu heart program/honolulu asia aging study. Hypertension (2010) 55:1352-9. doi: 10.1161/hypertensionaha.109.147389

14. Parrott MD, Greenwood CE. Dietary influences on cognitive function with aging. Ann N Y Acad Sci. (2007) 1114:389-97. doi: 10.1196/annals.1396.028

15. Steptoe A, Kivimäki M. Stress and cardiovascular disease: an update on current knowledge. Annu Rev Public Health (2013) 34:337-54. doi: 10.1146/annurev-publhealth-031912-114452

16. Kowal P, Chatterji S, Naidoo N, Biritwum R, Fan W, Lopez Ridaura $\mathrm{R}$, et al. Data resource profile: the world health organization study on global ageing and adult health (SAGE). Int J Epidemiol. (2012) 41:1639-49. doi: 10.1093/ije/dys 210

17. Naidoo N. WHO Study on Global AGEing and Adult Health (SAGE) Waves 0 and 1 Sampling Information for China, Ghana, India, Mexico, Russia and South Africa. World Health Organization [Internet, 2012]. (2012). Available online at: http://www.who.int/healthinfo/sage/SAGEWorkingPaper5_ Wave1Sampling.pdf (Accessed March 23, 2018).

18. World Bank. World Bank List of Country Groups. [Internet, 2007]. (2007). Available online at: http://datatopics.worldbank.org/world-developmentindicators/the-world-by-income-and-region.html (Accessed March 23, 2018).

19. World Health Organization Appropriate body-mass index for Asian populations and its implications for policy and intervention strategies. Lancet (2004) 363:157-63. doi: 10.1016/s0140-6736(03)15268-3

20. Armstrong T, Bull F. Development of the world health organization global physical activity questionnaire (GPAQ). J Public Health (2006) 14:66-70. doi: 10.1007/s10389-006-0024-x

21. Mielke MM, Vemuri P, Rocca WA. Clinical epidemiology of Alzheimer's disease: assessing sex and gender differences. Clin Epidemiol. (2014) 6:37. doi: $10.2147 /$ clep.s37929

22. Jia J, Wang F, Wei C, Zhou A, Jia X, Li F, et al. The prevalence of dementia in urban and rural areas of China. Alzheimers Dement. (2014) 10:1-9. doi: 10.1016/j.jalz.2013.01.012 
23. UNESCO. International Standard Classification of Education. Geneva: UNESCO. [Internet, 1997]. (1997). Available online at: http://www.unesco. org/education/information/nfsunesco/doc/isced_1997.htm (Accessed March 23, 2018)

24. Aneni EC, Crippa A, Osondu CU, Valero-Elizondo J, Younus A, Nasir $\mathrm{K}$, et al. Estimates of mortality benefit from ideal cardiovascular health metrics: a dose response meta-analysis. J Am Heart Assoc. (2017) 6:e006904. doi: 10.1161/jaha.117.006904

25. Guo L, Zhang S. Association between ideal cardiovascular health metrics and risk of cardiovascular events or mortality: a meta-analysis of prospective studies. Clin Cardiol. (2017) 40:1339-46. doi: 10.1002/clc. 22836

26. Thacker EL, Gillett SR, Wadley VG, Unverzagt FW, Judd SE, McClure LA, et al. The American heart association life's simple 7 and incident cognitive impairment: the reasons for geographic and racial differences in stroke (REGARDS) study. J Am Heart Assoc. (2014) 3:e000635. doi: $10.1161 /$ jaha.113.000635

27. Younus A, Aneni EC, Spatz ES, Osondu CU, Roberson L, Ogunmoroti O, et al. A systematic review of the prevalence and outcomes of ideal cardiovascular health in US and non-US populations. Mayo Clin Proc. (2016) 91:649-70. doi: 10.1016/j.mayocp.2016.01.019

28. Snyder HM, Corriveau RA, Craft S, Faber JE, Greenberg SM, Knopman $\mathrm{D}$, et al. Vascular contributions to cognitive impairment and dementia including Alzheimer's disease. Alzheimers Dement. (2015) 11:710-7. doi: 10.1016/j.jalz.2014.10.008

29. Gehlich KH, Beller J, Lange-Asschenfeldt B, Köcher W, Meinke MC, Lademann J. Fruit and vegetable consumption is associated with improved mental and cognitive health in older adults from non-Western developing countries. Public Health Nutr. (2018) 1-8. doi: 10.1017/s136898001 8002525

30. Lademann J, Schanzer S, Meinke M, Sterry W, Darvin ME. Interaction between carotenoids and free radicals in human skin. Skin Pharmacol Physiol. (2011) 24:238-44. doi: 10.1159/000326074

31. Polidori MC, Praticó D, Mangialasche F, Mariani E, Aust O, Anlasik T, et al. High fruit and vegetable intake is positively correlated with antioxidant status and cognitive performance in healthy subjects. J Alzheimers Dis. (2009) 17:921-7. doi: 10.3233/jad-2009-1114

32. Yu RX, Köcher W, Darvin ME, Büttner M, Jung S, Lee BN, et al. Spectroscopic biofeedback on cutaneous carotenoids as part of a prevention program could be effective to raise health awareness in adolescents. J Biophoton. (2014) 7:926-37. doi: 10.1002/jbio.201300134

33. Borre YE, Panagaki T, Koelink PJ, Morgan ME, Hendriksen H, Garssen $\mathrm{J}$, et al. Neuroprotective and cognitive enhancing effects of a multitargeted food intervention in an animal model of neurodegeneration and depression. Neuropharmacology (2014) 79:738-49. doi: 10.1016/ j.neuropharm.2013.11.009

34. Calvani R, Picca A, Lo Monaco MR, Landi F, Bernabei R, Marzetti E. Of microbes and minds: a narrative review on the second brain aging. Front Med. (2018) 5:53. doi: 10.3389/fmed.2018.00053

35. McEwen BS, Sapolsky RM. Stress and cognitive function. Curr Opin Neurobiol. (1995) 5:205-16. doi: 10.1016/0959-4388(95)80028-x

36. Chapman B, Duberstein P, Tindle HA, Sink KM, Robbins J, Tancredi DJ, et al. Personality predicts cognitive function over 7 years in older persons. Int $J$ Geriatr Psychiatry (2012) 20:612-21. doi: 10.1097/jgp.0b013e31822cc9cb

37. Zufferey V, Donati A, Popp J, Meuli R, Rossier J, Frackowiak R, et al. Neuroticism, depression, and anxiety traits exacerbate the state of cognitive impairment and hippocampal vulnerability to Alzheimer's disease. Alzheimers Dement. (2017) 7:107-14. doi: 10.1016/j.dadm.2017.05.002

38. Yang Q, Zhang B, Deng P, Chen L, Wang JR, Fan DS. Assessing cardiovascular health using life's simple 7 in a chinese population undergoing stroke prevention. Chin Med J. (2015) 128:2450. doi: 10.4103/0366-6999. 164928

39. Uthman OA, Hartley L, Rees K, Taylor F, Ebrahim, S, Clarke A. (2015). Multiple risk factor interventions for primary prevention of cardiovascular disease in low-and middle-income countries. Cochrane Database Syst. Rev. (2015) 8:CD011163. doi: 10.1002/14651858.cd011163.pub2

Conflict of Interest Statement: The authors declare that the research was conducted in the absence of any commercial or financial relationships that could be construed as a potential conflict of interest.

Copyright (c) 2018 Gildner, Ng, Wu, Guo, Snodgrass and Kowal. This is an openaccess article distributed under the terms of the Creative Commons Attribution License (CC BY). The use, distribution or reproduction in other forums is permitted, provided the original author(s) and the copyright owner(s) are credited and that the original publication in this journal is cited, in accordance with accepted academic practice. No use, distribution or reproduction is permitted which does not comply with these terms. 